\title{
Association between Particulate Matter Air Pollution and Hospital Emergency Room Visits for Pneumonia with Septicemia: A Retrospective Analysis
}

\author{
Fu-Jen Cheng ${ }^{1,2}$, Kuo-Hsin Lee ${ }^{3}$, Chia-Wei Lee ${ }^{2}$, Ping-Chi Hsu ${ }^{2 *}$ \\ ${ }^{1}$ Department of Emergency Medicine, Kaohsiung Chang Gung Memorial Hospital, Chang Gung University College of \\ Medicine, Kaohsiung 83301, Taiwan \\ ${ }^{2}$ Department of Safety, Health and Environmental Engineering, National Kaohsiung University of Science and \\ Technology, Kaohsiung 81164, Taiwan \\ ${ }^{3}$ Department of Emergency Medicine, E-Da Hospital, I-Shou University, Kaohsiung 82445, Taiwan
}

\begin{abstract}
Pneumonia is an inflammatory condition of the lungs caused by infection, which may be triggered and exacerbated by particulate matter (PM) exposure. We aimed to estimate the effect of PM on emergency department (ED) visits in pneumonia patients with septicemia after controlling for gaseous pollutants. Measurements on $\mathrm{PM}_{2.5}, \mathrm{PM}_{10}$, and other air pollutants at each of the 11 air-quality monitoring stations in Kaohsiung City, Taiwan, were collected between 2007 and 2013. The medical records of non-trauma patients who were over 17 years old and had visited the ED with a principal diagnosis of pneumonia were extracted. Poisson models were used to examine the relationship between air pollutants and daily ED visits for pneumonia with septicemia. Interquartile increments in the levels of $\mathrm{PM}_{2.5}, \mathrm{PM}_{10}$, and $\mathrm{NO}_{2}$ at lag 0 were associated with increments of $25.5 \%, 21.61 \%$, and $21.97 \%$, respectively, in the number of ED visits for pneumonia with septicemia during the warm season. The effect estimates of $\mathrm{PM}_{2.5}$ were robust after adjusting for $\mathrm{PM}_{10}$ and $\mathrm{NO}_{2}$ in the twopollutant model. $\mathrm{PM}_{2.5}$ had stronger associations with $\mathrm{ED}$ visits in the cases of pneumonia with septicemia in relatively healthy patients, such as those without comorbid hypertension, diabetes, stroke, liver cirrhosis, respiratory disease, or malignancy. In conclusion, although the existing evidence already supports a causal relationship between $\mathrm{PM}_{2.5}$ and pulmonary dysfunction, we propose that $\mathrm{PM}_{2.5}$ may also play an important role in emergency visits for pneumonia with septicemia during the warm season in southern Taiwan after adjusting for $\mathrm{PM}_{10}$ and $\mathrm{NO}_{2}$, especially among relatively healthy residents.
\end{abstract}

Keywords: Air pollution; Particulate matter; Pneumonia; Septicemia; Emergency department.

\section{LIST OF ABBREVIATIONS}

CI: Confidence interval. CRP: C-reactive protein. ED: Emergency department. OHCA: Out-of-hospital cardiac arrest. OR: Odds ratio.

PM: Particulate matter.

WBC: White blood cells.

IQR: Interquartile range.

$\mathrm{PM}_{\mathrm{C}}$ : Coarse particulate matter.

\footnotetext{
${ }^{*}$ Corresponding author.

Tel.: +886-7-6011000 ext. 32322; Fax: +886-7-6011061

E-mail address: pchsu@nkust.edu.tw
}

\section{INTRODUCTION}

Over the past decade, several epidemiological studies have demonstrated positive associations between ambient levels of particulate matter (PM) and daily mortality as well as hospital admissions or emergency department (ED) visits in the case of cardiovascular and respiratory morbidities, such as asthma, chronic obstructive pulmonary disease, and myocardial infarction (Cheng et al., 2015; Haikerwal et al., 2016; Weichenthal et al., 2016). Fine particles (defined as PM with an aerodynamic diameter smaller than $2.5 \mu \mathrm{m} ; \mathrm{PM}_{2.5}$ ) are seen as a great health and regulatory concern, with epidemiological studies suggesting that $\mathrm{PM}_{2.5}$ may exert greater toxicity than larger particles (Wang et al., 2015; Xing et al., 2016). Toxicological studies have demonstrated that PM exposure may impact respiratory health by inducing both lung inflammation and systemic inflammation (Tamagawa et al., 2008; Hajat et al., 2015; Li et al., 2017; Maciejczyk et al., 2018).

Pneumonia is an inflammatory condition of the lungs, 
and pneumonia with septicemia may cause systemic inflammation, which may also be triggered and exacerbated by fine particles. However, only a few studies have examined the association between PM and pneumonia, and the results have been inconsistent (Lin et al., 2005; Cheng et al., 2009). Several multi-city studies have suggested regional heterogeneity in the estimated effect of PM on mortality and hospitalization (Dominici et al., 2003; Franklin et al., 2007; Ueda et al., 2012; Kim et al., 2018). Seasonal variation has also been found to affect the estimates of PM effects (Bell et al., 2009; Tian et al., 2015). These regional and seasonal variations are partly explained by community characteristics, such as air conditioning (Bell et al., 2008), population density (Zeka et al., 2005), proportion of elderly residents (Katsouyanni et al., 2001), background location (Grivas et al., 2018), and effect modification by ambient temperature (Cheng et al., 2015). Some studies have found that patients with comorbidities may show an increased risk of pneumonia and myocardial infarction, considering the air pollutant levels (Cheng et al., 2009; Pope et al., 2015).

The present study obtained data on events of pneumonia with septicemia, over a period of 7 years, from a tertiary academic medical center in southern Taiwan with a registry of well-characterized patients who visited the ED due to pneumonia. These data were linked to air pollution and weather data and analyzed using a case-crossover design. This study had two specific objectives: (1) to evaluate the effects of increases in the short-term exposure to $\mathrm{PM}_{2.5}$ on events of pneumonia with septicemia and (2) to explore the potential triggering effects of $\mathrm{PM}_{2.5}$, specifically for persons with preexisting disease.

\section{METHODS}

\section{Kaohsiung City}

Kaohsiung is the largest commercial harbor and the second largest city in Taiwan, with a population of approximately 2.77 million people. It is the chief center of the heavy industry, including the China Steel Corporation and China Shipbuilding Corporation, and of the petrochemical industry and is situated on the southwest coast of Taiwan. The city is considered a symbol of recent success in Taiwan's economic development.

\section{ED Pneumonia Patients with Septicemia}

A retrospective observational study was conducted between January 1, 2007, and December 31, 2013, in an urban tertiary medical center with an average of 72,000 ED visits per year. This study was retrospectively registered at Kaohsiung Chang Gung Memorial Hospital on August 27, 2017; the study was approved by Chang Gung Memorial Hospital's institutional review board and has been carried out in accordance with the Code of Ethics of the World Medical Association (Declaration of Helsinki), registration no. 201701059B0C501. The medical records of non-trauma patients aged over 17 years, who had visited the ED with a principal diagnosis of pneumonia (International Classification of Diseases, ninth revision [ICD-9]: 480-486) with septicemia (ICD-9: 038) were extracted from the ED's administrative database. Data on age, sex, and the risk factors for pneumonia, including hypertension, diabetes, malignancy, congestive heart failure, respiratory disease, liver cirrhosis, chronic kidney disease, and cerebellar infarction, were collected from the medical record charts of patients (Lim et al., 2003).

\section{Pollutant and Meteorological Data}

Eleven air-quality monitoring stations were established in Kaohsiung City in 1994 by the Taiwanese Environmental Protection Administration (EPA), a central governmental agency. The stations use commercial monitoring instruments designated by USEPA as an equivalent or reference method, and manufactured by Thermo Environmental Instruments Inc. (Franklin, MA, USA). The monitoring stations are fully automated and routinely monitor the levels of five "criteria" pollutants, including sulfur dioxide $\left(\mathrm{SO}_{2}\right)$ (by ultraviolet fluorescence), PM with an aerodynamic diameter smaller than $10 \mu \mathrm{m}\left(\mathrm{PM}_{10}\right)$ (by beta-ray absorption), $\mathrm{PM}_{2.5}$ (by beta-ray absorption), nitrogen dioxide $\left(\mathrm{NO}_{2}\right)$ (by ultraviolet fluorescence), and ozone $\left(\mathrm{O}_{3}\right)$ (by ultraviolet photometry). For each day, hourly air pollution data were obtained from all the monitoring stations. The addresses of the patients were collected from their medical records, and the 24-hour average levels of these pollutants were computed from the nearest monitoring station. Daily recordings of mean temperature and mean humidity were also collected from the monitoring stations.

\section{Statistical Analysis}

Data were analyzed using the case-crossover technique (Maclure, 1991; Marshall and Jackson, 1993; Mittleman et al., 1995). This design is an alternative to the Poisson time series regression models for studying the short-term effects attributed to air pollutants. Single-day lags from the current day (lag 0 ) and 1-3 days prior to the pneumonia event (lag 1, lag 2, and lag 3) were examined separately. In the casecrossover design, within-subject comparisons were performed between a case period and control periods. A case period was defined as the date of a patient's ED visit. For control periods, we chose the same day of the week in the same month of the same year as the case period. This control selection strategy was expected to adjust for the effects of long-term trends, seasonality, and day of the week, by design (Peng et al., 2005). We estimated the odds ratios (ORs) and 95\% confidence intervals (CIs) of the cases of pneumonia associated with $\mathrm{PM}_{2.5}$ mass and each air pollutant component using conditional logistic regression. Subgroup analyses by sex, age, and underlying disease groups were also performed to identify the most susceptible subpopulations.

Both single-pollutant models and multi-pollutant models were fitted with different combinations of pollutants (up to two pollutants per model) to assess the stability of the effects of PM. Exposure levels to air pollutants were entered into the models as continuous variables. Meteorological variables, such as daily average temperature and humidity on the same day, which may play a confounding role, were included in the model. The ORs were calculated on the basis of an interquartile range (IQR) increment in the 
$\mathrm{PM}_{2.5}, \mathrm{PM}_{10}, \mathrm{NO}_{2}, \mathrm{SO}_{2}$, and $\mathrm{O}_{3}$ exposure. The criterion for significance was set at $\mathrm{p}<0.05$. All analyses were performed using SAS software version 9.3 (SAS Institute, Cary, North Carolina, USA).

\section{RESULTS}

During the seven-year study period, a total of 4,827 visits to the ED were recorded for cases of pneumonia with septicemia. A total of 812 patients were excluded from the analysis because they did not reside in Kaohsiung City; the remaining 4,015 patients comprised our study group. The demographic characteristics of the 4,015 patients are listed in Table 1.

Of these patients, $2,545(63.5 \%)$ were male and the mean age was 67.2 years. Hypertension $(27.0 \%)$, respiratory disease $(21.5 \%)$, and diabetes $(20.0 \%)$ were the most frequently reported underlying diseases.

A summary of the meteorological factors and daily mean concentrations of air pollutants, as well as weather variables in Kaohsiung during the study period, is presented in Table 2. The average $\mathrm{PM}_{2.5}$ concentration over the study period was $43.7 \mu \mathrm{g} \mathrm{m}^{-3}$. There were seasonal variations in the concentrations of all the pollutants between the cold (October to March) and warm (April to September) seasons. The levels of $\mathrm{PM}_{2.5}, \mathrm{PM}_{10}, \mathrm{NO}_{2}, \mathrm{SO}_{2}$, and $\mathrm{O}_{3}$ were significantly higher during the cold season $(\mathrm{p}<0.001)$, whereas the temperature and humidity were significantly higher during the warm season $(\mathrm{p}<0.001)$.

Pearson's correlation coefficients for the air pollutants and weather conditions are presented in Table $3 . \mathrm{PM}_{2.5}$ was highly correlated with $\mathrm{PM}_{10}(\mathrm{r}=0.924 ; \mathrm{p}<0.0001), \mathrm{NO}_{2}$

Table 1. Demographic characteristic of patients.

\begin{tabular}{lll}
\hline All & Number $=4015$ & $\%$ \\
\hline Demographic characteristics of patients & & \\
Age (mean \pm SD) & $(67.22 \pm 17.13)$ & 63.5 \\
Males & 2545 & 21.5 \\
Respiratory disease & 863 & 27.0 \\
Hypertension & 1085 & 20.0 \\
Diabetes & 802 & 12.3 \\
Past history of stroke & 492 & 3.0 \\
Liver cirrhosis & 121 & 7.0 \\
Heart failure & 283 & 7.9 \\
Renal insufficiency & 317 & 17.9 \\
Malignancy & 719 & 1.6 \\
Leukemia & 66 & 2.8 \\
Parkinsonism & 113 & \\
\hline SD: Stancris
\end{tabular}

SD: Standard deviation.

Table 2. Summary statistics for meteorological factors and air pollution in Kaohsiung, 2007-2013.

\begin{tabular}{|c|c|c|c|c|c|c|c|c|c|c|}
\hline & \multirow{2}{*}{ Minimum } & \multicolumn{3}{|c|}{ Percentiles } & \multirow{2}{*}{ Maximum } & \multirow{2}{*}{ Mean } & \multirow{2}{*}{$\begin{array}{l}\text { Warm season } \\
(\text { Mean } \pm \mathrm{SD})\end{array}$} & \multirow{2}{*}{$\begin{array}{l}\text { Cold season } \\
(\text { Mean } \pm \text { SD) }\end{array}$} & \multirow{2}{*}{$\mathrm{p}$} & \multirow{2}{*}{ IQR } \\
\hline & & $25 \%$ & $50 \%$ & $75 \%$ & & & & & & \\
\hline $\mathrm{PM}_{2.5}$ & 10.75 & 25.01 & 42.98 & 57.64 & 135.26 & 43.72 & $30.63 \pm 15.18$ & $56.83 \pm 17.16$ & $<0.001$ & 32.63 \\
\hline $\mathrm{PM}_{10}$ & 14.69 & 44.14 & 72.38 & 98.53 & 581.96 & 74.65 & $52.06 \pm 23.07$ & $97.10 \pm 31.15$ & $<0.001$ & 54.39 \\
\hline $\mathrm{NO}_{2}$ & 3.92 & 13.64 & 18.83 & 25.14 & 45.24 & 19.60 & $14.49 \pm 4.61$ & $24.76 \pm 5.74$ & $<0.001$ & 11.50 \\
\hline $\mathrm{SO}_{2}$ & 2.02 & 5.15 & 6.57 & 8.26 & 17.65 & 6.83 & $6.20 \pm 2.09$ & $7.45 \pm 2.18$ & $<0.001$ & 3.10 \\
\hline $\mathrm{O}_{3}$ & 3.51 & 19.19 & 28.25 & 37.73 & 74.60 & 29.24 & $28.33 \pm 13.18$ & $30.14 \pm 11.55$ & $<0.001$ & 18.54 \\
\hline Temperature & 12.41 & 22.40 & 26.42 & 28.75 & 32.11 & 25.34 & $28.25 \pm 1.99$ & $22.41 \pm 3.58$ & $<0.001$ & 6.35 \\
\hline Humidity & 43.97 & 69.84 & 73.91 & 78.08 & 95.32 & 74.02 & $75.80 \pm 6.69$ & $72.23 \pm 7.27$ & $<0.001$ & 8.24 \\
\hline
\end{tabular}

IQR: Interquartile range; SD: Standard deviation; PM: Particulate matter.

Table 3. Spearman's correlation coefficients for air pollutants and weather conditions in the study period.

\begin{tabular}{llllllll}
\hline & $\mathrm{PM}_{2.5}$ & $\mathrm{PM}_{10}$ & $\mathrm{NO}_{2}$ & $\mathrm{SO}_{2}$ & $\mathrm{O}_{3}$ & TEMP & Humidity \\
\hline $\mathrm{PM}_{2.5}$ & 1.000 & 0.924 & 0.810 & 0.508 & 0.439 & -0.573 & -0.392 \\
$\mathrm{PM}_{10}$ & & 1.000 & 0.762 & 0.489 & 0.417 & -0.540 & -0.418 \\
$\mathrm{NO}_{2}$ & & 1.000 & 0.550 & 0.118 & -0.749 & -0.299 \\
$\mathrm{SO}_{2}$ & & & 1.000 & 0.209 & -0.255 & -0.330 \\
$\mathrm{O}_{3}$ & & & & & 1.000 & 0.094 & -0.378 \\
Temperature & & & & & & 1.000 & 0.228 \\
Humidity & & & & & & & 1.000 \\
\hline
\end{tabular}

PM: Particulate matter. 
$(\mathrm{r}=0.810 ; \mathrm{p}<0.0001)$, and $\mathrm{SO}_{2}(\mathrm{r}=0.508 ; \mathrm{p}<0.0001)$. The year-round and season-specific estimates of the pollutants' effects are presented in Fig. 1. During the warm season, an IQR increase in the levels of $\mathrm{PM}_{2.5}, \mathrm{PM}_{10}$, and
$\mathrm{NO}_{2}$ had associated effects at lag 0, at increments of 25.5\% (95\% CI: 8.06-45.71\%), 21.61\% (95\% CI: 1.59-45.58\%) and $21.97 \%$ (95\% CI: $1.51-46.55 \%)$, respectively, in the frequency of ED visits for pneumonia with septicemia. An a

$\mathrm{PM}_{2.5}, \mu \mathrm{g} / \mathrm{m}^{3}$
$\operatorname{lag} 0$
$\operatorname{lag} 1$
$\operatorname{lag} 2$
$\operatorname{lag} 3$
$\mathrm{PM}_{10}, \mu \mathrm{g} / \mathrm{m}^{3}$
$\operatorname{lag} 0$
$\operatorname{lag} 1$
$\operatorname{lag} 2$
$\operatorname{lag} 3$
$\mathrm{NO}_{2}, \mathrm{ppb}$
$\operatorname{lag} 0$
$\operatorname{lag} 1$
$\operatorname{lag} 2$
$\operatorname{lag} 3$
$\mathrm{SO}_{2}, \mathrm{ppb}$
$\operatorname{lag} 0$
$\operatorname{lag} 1$
$\operatorname{lag} 2$
$\operatorname{lag} 3$
$\mathrm{O}_{3}, \mathrm{ppb}$
$\operatorname{lag} 0$
$\operatorname{lag} 1$
$\operatorname{lag} 2$
$\operatorname{lag} 3$

0.8

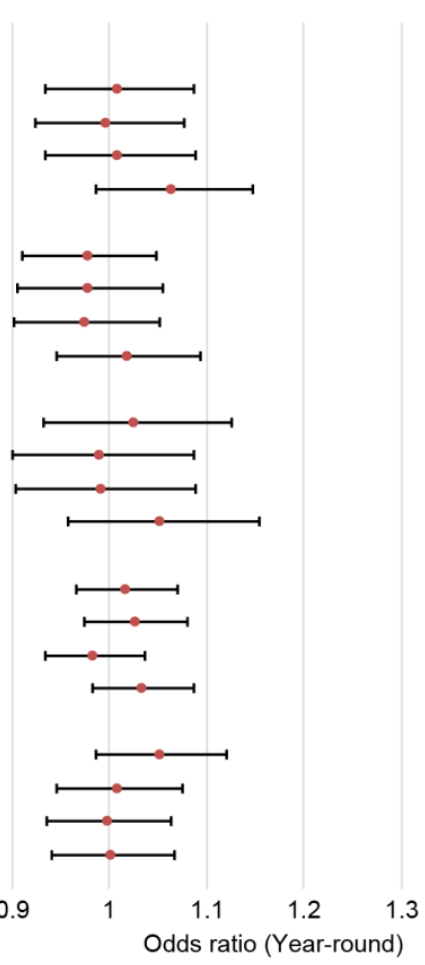

C b

$\mathrm{PM}_{2.5}, \mu \mathrm{g} / \mathrm{m}^{3}$

$\operatorname{lag} 0$

$\operatorname{lag} 1$

lag 2

lag 3

$\mathrm{PM}_{10}, \mu \mathrm{g} / \mathrm{m}^{3}$

lag 0

lag 1

lag 2

lag 3

$\mathrm{NO}_{2}, \mathrm{ppb}$

lag 0

lag 1

$\operatorname{lag} 2$

$\operatorname{lag} 3$

$\mathrm{SO}_{2}, \mathrm{ppb}$

lag 0

lag 1

lag 2

$\operatorname{lag} 3$
$\mathrm{ppb}$

$\mathrm{O}_{3}$, ppb

$\operatorname{lag} 0$
$\operatorname{lag} 1$

lag 2

lag 3

0.8
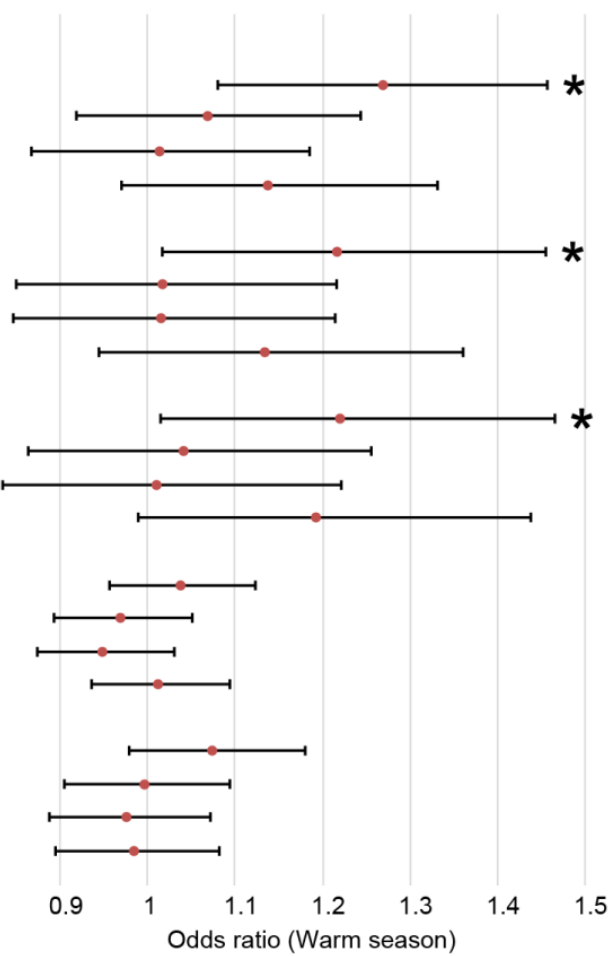

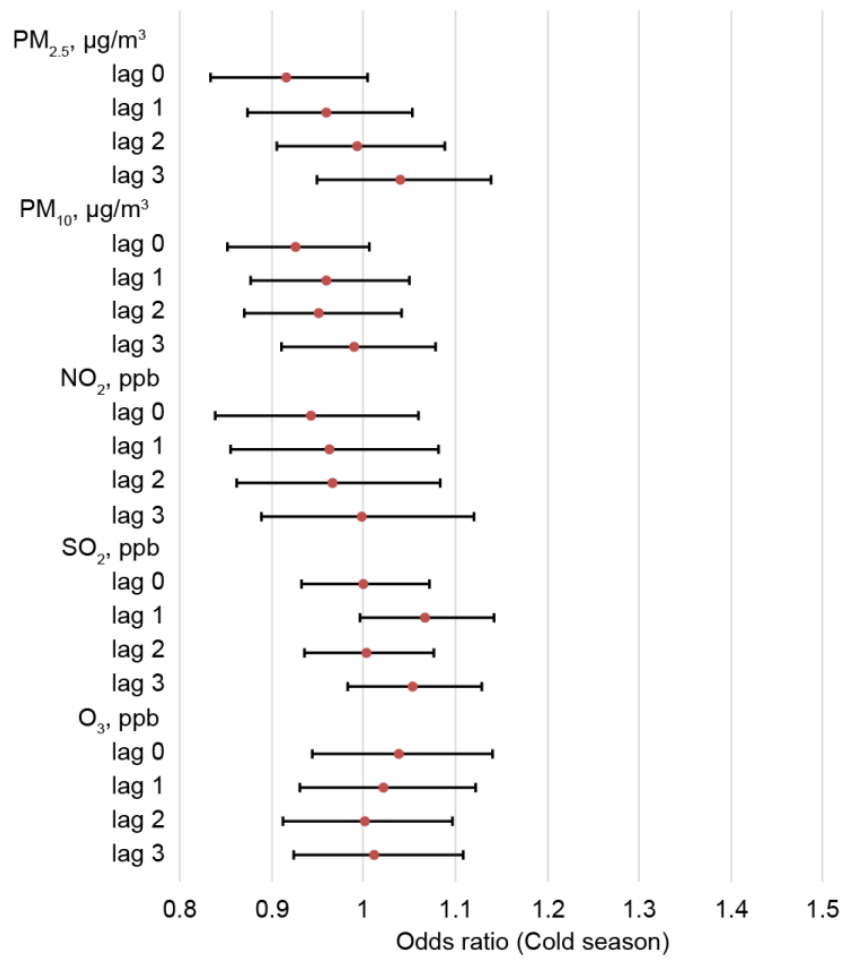

Fig. 1. OR (95\% CI) for ED visits for pneumonia with septicemia, associated with IQR increase in air pollutants. Adjustments were made for temperature and humidity. OR: odds ratio; CI: confidence interval; IQR: interquartile range; ED: emergency department; PM: particulate matter. 
IQR increase in the levels of $\mathrm{PM}_{2.5}, \mathrm{PM}_{10}, \mathrm{NO}_{2}, \mathrm{SO}_{2}$, and $\mathrm{O}_{3}$ was not significantly associated with $\mathrm{ED}$ visits for pneumonia with septicemia cases, overall and for the cold season. The association between PM and pneumonia with septicemia was strongest at lag 0 and decreased gradually in the later lags. Stronger associations were observed in the warm season.

A two-pollutant model was used to gain insight into which individual contaminant may influence the number of pneumonia with septicemia ED visits, independently of the effects of the other pollutants (Table 4). In the multipollutant models, we simultaneously included $\mathrm{PM}_{2.5}, \mathrm{PM}_{10}$, and $\mathrm{NO}_{2}$ during the warm season, based on the results of the single-pollutant models. The results of this analysis are shown in Table 4. An IQR increase in $\mathrm{PM}_{2.5}$ was significantly associated with ED visits for pneumonia with septicemia after adjusting for $\mathrm{PM}_{10}(\mathrm{OR}=1.413 ; 95 \% \mathrm{CI}$ : $1.043-1.914)$ and $\mathrm{NO}_{2}(\mathrm{OR}=1.213 ; 95 \% \mathrm{CI}: 1.025-1.436)$. An IQR increase in $\mathrm{PM}_{10}$ was not significantly associated with ED visits for pneumonia with septicemia after adjusting for $\mathrm{PM}_{2.5}(\mathrm{OR}=0.848 ; 95 \% \mathrm{CI}: 0.588-1.224)$ and $\mathrm{NO}_{2}(\mathrm{OR}=$ 1.145 ; 95\% CI: $0.935-1.401)$.

Fig. 2 shows the results of the stratified analysis to examine the effects of $\mathrm{PM}_{2.5}$ on pneumonia with septicemia cases during the warm season by differential underlying diseases. $\mathrm{PM}_{2.5}$ was significantly associated with pneumonia

Table 4. OR (95\% CI) of pneumonia-with-septicemia ED visits for each interquartile change in two-pollutant model.

\begin{tabular}{llll}
\hline Adjusted for temperature, humidity and pollutant & Adjust $\mathrm{PM}_{2.5}$ & Adjust $\mathrm{PM}_{10}$ & Adjust $\mathrm{NO}_{2}$ \\
\hline $\mathrm{PM}_{2.5}$ & & $1.413(1.043-1.914)$ & $1.213(1.025-1.436)$ \\
$\mathrm{PM}_{10}$ & $0.848(0.588-1.224)$ & & $1.145(0.935-1.401)$ \\
$\mathrm{NO}_{2}$ & $1.095(0.891-1.347)$ & $1.146(0.933-1.408)$ & \\
\hline
\end{tabular}

OR: Odds ratio; PM: Particulate matter; CI: Confidence interval.

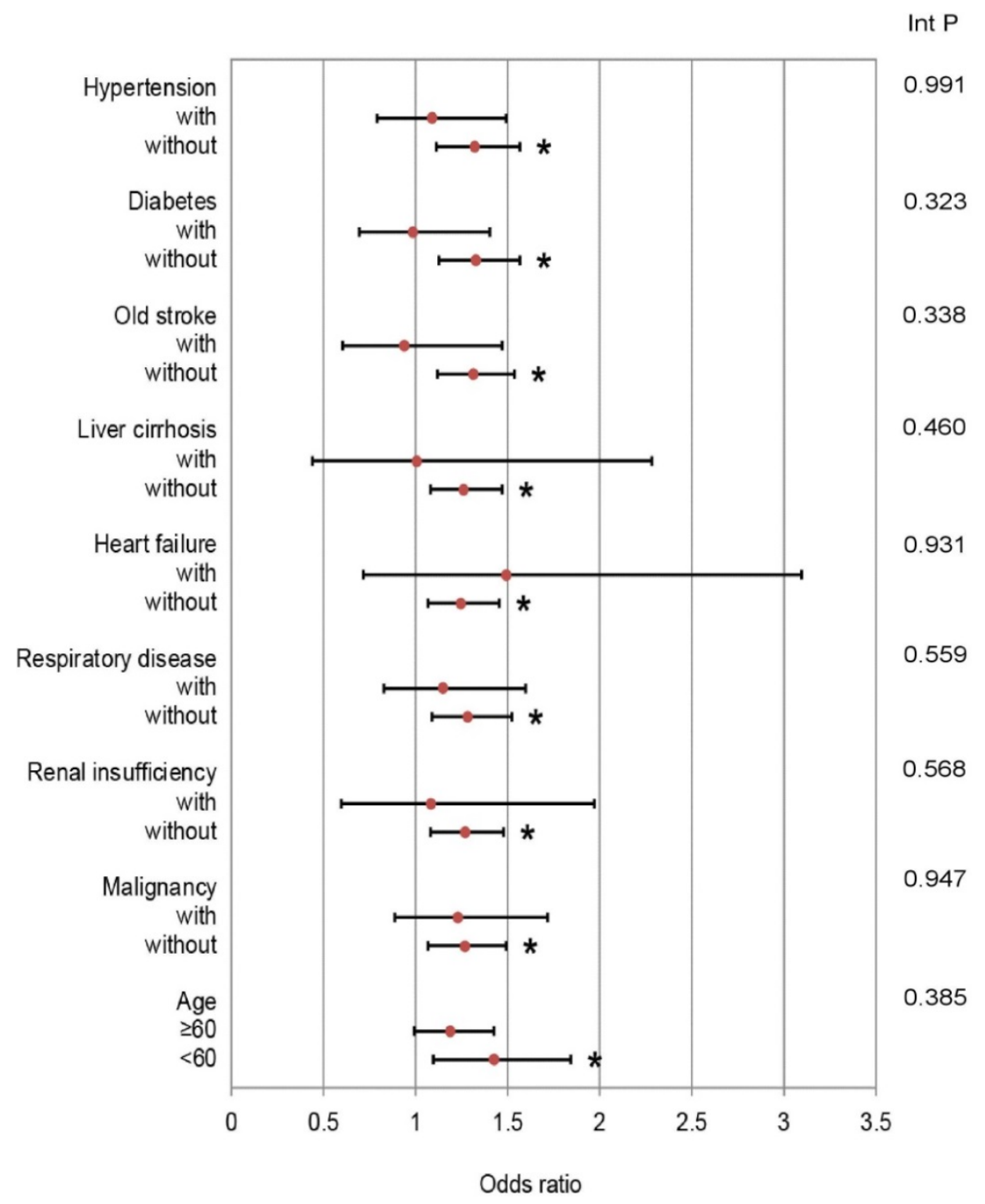

Fig. 2. ORs after adjustment for temperature and humidity, with an interquartile increase in $\mathrm{PM}_{2.5}{ }^{*} \mathrm{p}<0.05$; Int $\mathrm{P}$ : interaction p-value; PM: particulate matter. 
in relatively healthy patients, such as those without hypertension $(\mathrm{OR}=1.317 ; 95 \% \mathrm{CI}$ : $1.110-1.563)$, diabetes $(\mathrm{OR}=1.330 ; 95 \% \mathrm{CI}: 1.126-1.569)$, old stroke $(\mathrm{OR}=1.309$; 95\% CI: $1.116-1.536)$, liver cirrhosis $(\mathrm{OR}=1.263 ; 95 \%$ CI: $1.084-1.470)$, respiratory disease $(\mathrm{OR}=1.265 ; 95 \%$ CI: $1.084-1.476)$, renal insufficiency $(\mathrm{OR}=1.265 ; 95 \%$ CI: $1.084-1.476)$, or malignancy (OR $=1.264 ; 95 \% \mathrm{CI}$ : 1.068-1.495), and those of a younger age (OR = 1.423; 95\% CI: 1.097-1.845), but the difference did not achieve statistical significance, as all interaction p-values were $>0.05$. The OR was slightly higher in patients with heart failure $(\mathrm{OR}=1.492 ; 95 \% \mathrm{CI}: 0.718-3.100)$ than in those without $(\mathrm{OR}=1.246 ; 95 \% \mathrm{CI}: 1.069-1.452)$, but the difference did not achieve statistical significance (interaction $\mathrm{p}=0.931$ ).

\section{DISCUSSION}

In this study, we estimated the effect of PM on ED visits in pneumonia patients with septicemia and found that $\mathrm{PM}_{2.5}$, $\mathrm{PM}_{10}$, and $\mathrm{NO}_{2}$ may play an important role in emergency visits for pneumonia with septicemia in Kaohsiung during the warm season. Recent studies have demonstrated that ambient air pollutants have varying health impacts. $\mathrm{PM}_{10}$, $\mathrm{NO}_{2}, \mathrm{CO}$, and $\mathrm{SO}_{2}$ were found to have significant associations with cases of out-of-hospital cardiac arrests (OHCAs) (Kang et al., 2016). In another study, increased levels of $\mathrm{SO}_{2}$ and $\mathrm{NO}_{2}$ were associated with cardiovascular diseaseassociated mortality (Liu et al., 2015), in which $\mathrm{PM}_{10}$ was not associated with cardiovascular disease-related mortality. $\mathrm{PM}_{2.5}, \mathrm{PM}_{10}, \mathrm{SO}_{2}$, and $\mathrm{NO}_{2}$ were also related to respiratoryrelated emergency visits among children (Ilabaca et al., 1999). $\mathrm{O}_{3}$ and $\mathrm{PM}_{10}$ were associated with hemorrhagic stroke (Han et al., 2016). $\mathrm{PM}_{2.5}$ was found to be associated with several different diseases, such as OHCA, myocardial infarction, stroke, and respiratory mortality (Gardner et al., 2014; Huang et al., 2016; Ueda et al., 2016; Ren et al., 2017). Cheng et al. (2009) demonstrated that on warm days, $\mathrm{PM}_{10}, \mathrm{NO}_{2}$, and $\mathrm{CO}$ were associated with pneumonia admissions. In Cheng's study, pneumonia admissions were associated with $\mathrm{PM}_{10}, \mathrm{NO}_{2}$, and $\mathrm{CO}$ and were similar for patients with or without comorbid diabetes, hypertension, and asthma. However, $\mathrm{PM}_{2.5}$ was not included in that study. Another study revealed that coarse PM $\left(\mathrm{PM}_{\mathrm{C}}\right.$, defined as PM with an aerodynamic diameter between $2.5 \mu \mathrm{m}$ and $10 \mu \mathrm{m}$ ) and $\mathrm{PM}_{2.5}$ were significantly associated with emergency pneumonia hospitalizations (Qiu et al., 2014). In our study, we observed a significant association between $\mathrm{PM}_{2.5}$, $\mathrm{PM}_{10}$, and $\mathrm{NO}_{2}$ and pneumonia with septicemia $\mathrm{ED}$ visits. Furthermore, $\mathrm{PM}_{2.5}$ seemed to be associated with pneumonia in relatively healthy patients, but the differences between subgroups with and without underlying disease did not achieve statistical significance.

This difference may be attributed to variances in the patient groups between the studies. Previous studies included patients admitted for pneumonia; we included ED visits for pneumonia patients with septicemia. In the present study, we attempted to identify patients with different underlying diseases and who had a higher sensitivity to air pollutants. We found stronger associations between PM concentrations and pneumonia with septicemia ED visits in patients without comorbid hypertension, diabetes, old stroke, liver cirrhosis, respiratory disease, renal insufficiency, and malignancy and those of a younger age; however, the differences did not achieve statistical significance. These results are different from those of previous studies. Qiu et al. (2014) showed that $\mathrm{PM}_{2.5}$ and $\mathrm{PM}_{\mathrm{C}}$ were associated with emergency hospital admissions for pneumonia, especially among women, children, and elderly adults ( $\geq 65$ years old).

One possible reason for the different results between Qiu's study and the present study could be that the study populations were different; we only included patients with pneumonia with septicemia, whereas previous studies included pneumonia patients with or without septicemia. Second, patients with underlying diseases had higher rates of septicemia (Salive et al., 1993; Storms et al., 2017); the underlying condition might be the major confounding factor that overcomes the PM effect. Third, patients with underlying conditions or advanced age might spend more time indoors, due to bedridden or limited activity conditions. These situations might limit their PM exposure. Our study is one of the few that focuses on PM in the context of pneumonia with septicemia. Therefore, further studies are needed to clarify the relationship between pneumonia with septicemia and PM, especially for subgroup analysis.

In many previous epidemiological studies, the time window for health effects of air pollution ranged 0-3 days. Huang et al. (2016) found that short-term exposure to PM was positively associated with hospital admissions for ischemic and hemorrhagic stroke on lag 0 on warm days. Kang et al. (2016) found the highest OR of OHCA for $\mathrm{PM}_{2.5}$ was observed at lag 2. For respiratory diseases, $\mathrm{PM}_{2.5}$ was associated with pneumonia hospital admissions on lag 0-2 (Cheng et al., 2015) and for asthma on lag 0 (Haikerwal et al., 2016). Qiu et al. (2014) revealed that the highest OR of emergency pneumonia hospitalizations for $\mathrm{PM}_{2.5}$ and $\mathrm{PM}_{\mathrm{C}}$ was observed on lag $0-3$. The present study had similar result, which demonstrated that $\mathrm{PM}_{2.5}$ played an important role in emergency visits for pneumonia with septicemia on lag 0 . A human study showed that PM was associated with elevation of different cytokines on different lag days (Hassanvand et al., 2017), and this might be the reason for the different health impacts on different time lags of PM.

Several previous studies tried to clarify the mechanism underlying the relationship between air pollutants and lung inflammation. Several animal studies have shown an association between PM and lung inflammation. Zosky et al. (2014) found that geogenic particles induced an acute inflammatory response that peaked at 6 hours postexposure and a deficit in lung mechanics that peaked at 7 days post-exposure in mice. $\mathrm{PM}_{2.5}$ inhalation was related to multiple mechanisms associated with lung inflammation, such as an increase in epidermal growth factor receptormediated lung inflammation, plasminogen activator inhibitor-1, and interleukin 6 IL-6)-dependent activation of coagulation (Budinger et al., 2011; Jin et al., 2017). $\mathrm{PM}_{10}$ exposure was also found to be associated with lung 
inflammation through the inclusion of the recruitment of neutrophils and the induction of $\mathrm{T}$ helper 1 cell-related cytokine release, impairing lung function and increasing viral load and exacerbating the response to respiratory viral infection (Clifford et al., 2015; Huang et al., 2017). Some human studies have also explored the association among $\mathrm{PM}_{2.5}, \mathrm{PM}_{10}$, and systemic inflammation. Li et al. (2017) found that $\mathrm{PM}_{2.5}$ exposure was associated with elevated C-reactive protein (CRP) and tumor necrosis factor receptor 2 (TNFR2), which were associated with inflammation. Hassanvand et al. (2017) also revealed that $\mathrm{PM}_{2.5}$ exposure was associated with elevated levels of white blood cells (WBCs), high-sensitivity CRP, von Willebrand factor (vWF), and IL-6. The same study also found that $\mathrm{PM}_{10}$ exposure was associated with elevated WBC, IL-6, and vWF levels. WBC, IL-6, high-sensitivity CRP, and vWF are important for systemic inflammation (Hurst et al., 2001; Bernardo et al., 2004). Our study demonstrated that $\mathrm{PM}_{2.5}$ and $\mathrm{PM}_{10}$ were associated with $\mathrm{ED}$ visits for pneumonia with septicemia. This may be a result of the lung inflammation triggered and systemic inflammation enhanced by $\mathrm{PM}_{2.5}$ and $\mathrm{PM}_{10}$.

In the two-pollutant model, an IQR increase in $\mathrm{PM}_{2.5}$ was associated with an increase in the number of ED visits for pneumonia with septicemia, after adjusting for $\mathrm{PM}_{10}$. These findings suggest that some types of $\mathrm{PM}_{2.5}$ have a more hazardous effect than $\mathrm{PM}_{10}$. Similarly, Cheng et al. (2015) revealed that $\mathrm{PM}_{2.5}$ exerted the greatest effect on the rate of respiratory disease-related admissions, including pneumonia. Moreover, $\mathrm{PM}_{2.5}$ was associated with a higher number of inflammation and coagulation blood markers than $\mathrm{PM}_{10}$ (Bernardo et al., 2004). These findings suggest that $\mathrm{PM}_{2.5}$ plays a more important role in pneumonia and systemic inflammation than $\mathrm{PM}_{10}$. However, more evidence is necessary to uncover the underlying mechanism.

The hazardous effect of air pollutants appears to vary by season. Peng et al. (2005) explored the seasonal patterns in the short-term effects of PM on mortality, using data from 100 cities in the United States. Their analyses showed that the association between PM and mortality varied by region. Stronger associations were observed during the spring and summer in the northern regions, with no clear seasonal variation in the southern regions. Another study demonstrated that $\mathrm{PM}_{2.5}$ was associated with mortality, especially during transitional seasons (spring and autumn) (Ueda et al., 2016). Huang et al. (2016) stated that $\mathrm{PM}_{2.5}$, $\mathrm{PM}_{\mathrm{C}}$, and $\mathrm{PM}_{10}$ were positively associated with hospital admissions for ischemic and hemorrhagic stroke on warm days. Cheng et al. (2015) demonstrated that higher levels of $\mathrm{PM}_{\mathrm{C}}$ enhanced the risk of hospital admissions for respiratory diseases on cool days. Our study found that an IQR increase in $\mathrm{PM}_{2.5}, \mathrm{PM}_{10}$, and $\mathrm{NO}_{2}$ had associated effects on the frequency of ED visits for pneumonia with septicemia during the warm season. It is possible that a certain air pollutant or PM component, or a combination of several PM components, may contribute to seasonal variations in the health effects (Franklin et al., 2007; Ueda et al., 2016; Zeb et al., 2018). Another possible explanation for the seasonal variation in the health effects associated with $\mathrm{PM}_{2.5}$ is the difference in the personal exposure by season. During the cold season, the $\mathrm{PM}_{2.5}, \mathrm{PM}_{10}$, and $\mathrm{NO}_{2}$ levels are higher, and residents may more frequently use self-protective equipment, such as face masks, possibly leading to a lower exposure to air pollutants. Furthermore, differences in the number of open windows during different seasons in different regions may contribute to varying levels of air pollutant exposure, leading to differences in the effect, with a larger effect being noted in the case of a higher number of open windows (Bell et al., 2015). Further studies are required to clarify the reasons behind the seasonal variations in health effects.

There are several limitations to this study. First, this study included only one hospital, and the number of cases was limited. Second, this study was conducted in a tropical and industrial metropolitan city. These facts may somewhat restrict the generalizability of our findings to other locations with different meteorological and ethnic characteristics. Furthermore, factors such as air conditioning and personal protective equipment or time spent outdoors may affect personal exposure. This may modify the magnitude of the observed associations when they are compared to those at other geographical locations. Based on these limitations, future studies should include more hospitals, a larger sample size, and more regions.

\section{CONCLUSIONS}

Although the existing evidence already supports a causal relationship between $\mathrm{PM}_{2.5}$ and pulmonary dysfunction, we propose that $\mathrm{PM}_{2.5}, \mathrm{PM}_{10}$, and $\mathrm{NO}_{2}$ may also play an important role in emergency visits for pneumonia with septicemia during the warm season in southern Taiwan. The effects of $\mathrm{PM}_{2.5}$ were robust after adjusting for $\mathrm{PM}_{10}$ and $\mathrm{NO}_{2}$, especially among relatively healthy residents.

\section{ACKNOWLEDGMENTS}

We appreciate the support provided for statistics at Biostatistics Center, Kaohsiung Chang Gung Memorial Hospital. This study was supported in part by research grants from the Kaohsiung Chang Gung Memorial Hospital (CMRP-G8G0931) and partly supported by the Ministry of Science and Technology (MOST 105-2221-E-327-006MY2).

\section{DISCLAIMER}

The authors declare that they have no competing interests. The funders had no role in the study design, data collection and analysis, the decision to publish, or in the preparation of the manuscript.

\section{REFERENCES}

Bell, M.L., Ebisu, K., Peng, R.D., Walker, J., Samet, J.M, Zeger, S.L. and Dominici, F. (2008). Seasonal and regional short-term effects of fine particles on hospital admissions in 202 US counties, 1999-2005. Am. J. 
Epidemiol. 168: 1301-1310.

Bell, M.L., Ebisu, K., Peng, R.D. and Dominici, F. (2009). Adverse health effects of particulate air pollution: Modification by air conditioning. Epidemiology 20: 682-686.

Bernardo, A., Ball, C., Nolasco, L., Moake, J.F. and Dong, J.F. (2004). Effects of inflammatory cytokines on the release and cleavage of the endothelial cell-derived ultralarge von Willebrand factor multimers under flow. Blood 104: 100-106.

Budinger, G.R., McKell, J.L., Urich, D., Foiles, N., Weiss, I., Chiarella, S.E., Gonzalez, A., Soberanes, S., Ghio, A.J., Nigdelioglu, R., Mutlu, E.A., Radigan, K.A., Green, D., Kwaan, H.C. and Mutlu, G.M. (2011). Particulate matter-induced lung inflammation increases systemic levels of PAI-1 and activates coagulation through distinct mechanisms. PLoS One 6: e18525.

Burnett, R.T., Smith-Doiron, M., Stieb, D., Cakmak, S. and Brook, J.R. (1999). Effects of particulate and gaseous air pollution on cardiorespiratory hospitalizations. Arch. Environ. Health 54: 130-139.

Chauhan, A.J., Krishna, M.T., Frew, A.J. and Holgate, S.T. (1998). Exposure to nitrogen dioxide $\left(\mathrm{NO}_{2}\right)$ and respiratory disease risk. Rev. Environ. Health 13: 73-90.

Cheng, M.F., Tsai, S.S., Wu, T.N., Chen, P.S. and Yang, C.Y. (2007). Air pollution and hospital admissions for pneumonia in a tropical city: Kaohsiung, Taiwan. $J$. Toxicol. Environ. Health A 70: 2021-2026.

Cheng, M.F., Tsai, S.S., Chiu, H.F., Sung, F.C., Wu, T.N. and Yang, C.Y. (2009). Air pollution and hospital admissions for pneumonia: Are there potentially sensitive groups? Inhalation Toxicol. 21: 1092-1098.

Cheng, M.H., Chiu, H.F. and Yang, C.Y. (2015). Coarse particulate air pollution associated with increased risk of hospital admissions for respiratory diseases in a tropical city, Kaohsiung, Taiwan. Int. J. Environ. Res. Public Health 12: 13053-13068.

Clifford, H.D., Perks, K.L. and Zosky, G.R. (2015). Geogenic $\mathrm{PM}_{10}$ exposure exacerbates responses to influenza infection. Sci. Total Environ. 533: 275-282.

Dadvand, P., Nieuwenhuijsen, M.J., Agustí, À., de Batlle, J., Benet, M., Beelen, R., Cirach, M., Martinez, D., Hoek, G., Basagana, X., Ferrer, A., Ferrer, J., RodriguezRoisin, R., Sauleda, J., Guerra, S., Anto, J.M. and GarciaAymerich, J. (2014). Air pollution and biomarkers of systemic inflammation and tissue repair in COPD patients. Eur. Respir. J. 44: 603-613.

Dominici, F., McDermott, A., Zeger, S.L. and Samet, J.M. (2003). National maps of the effects of particulate matter on mortality: Exploring geographical variation. Environ. Health Perspect. 111: 39-44.

Franklin, M., Zeka, A. and Schwartz, J. (2007). Association between $\mathrm{PM}_{2.5}$ and all-cause and specificcause mortality in 27 US communities. J. Exposure Sci. Environ. Epidemiol. 17: 279-287.

Gardner, B., Ling, F., Hopke, P.K., Frampton, M.W., Utell, M.J., Zareba, W., Cameron, S.J., Chalupa, D., Kane, C., Kulandhaisamy, S., Topf, M.C. and Rich, D. (2014). Ambient fine particulate air pollution triggers ST-elevation myocardial infarction, but not non-ST elevation myocardial infarction: A case-crossover study. Part. Fibre Toxicol. 11: 1 .

Grivas, G., Cheristanidis, S., Chaloulakou, A., Koutrakis, P. and Mihalopoulos, N. (2018). Elemental composition and source apportionment of fine and coarse particles at traffic and urban background locations in Athens, Greece. Aerosol Air Qual. Res. 18: 1642-1659.

Haikerwal, A., Akram, M., Sim, M.R., Meyer, M., Abramson, M.J. and Dennekamp, M. (2016). Fine particulate matter $\left(\mathrm{PM}_{2.5}\right)$ exposure during a prolonged wildfire period and emergency department visits for asthma. Respirology 21: 88-94.

Hajat, A., Allison, M., Diez-Roux, A.V., Jenny, N.S., Jorgensen, N.W., Szpiro, A.A., Vadel, S. and Kaufman, J.D. (2015). Long-term exposure to air pollution and markers of inflammation, coagulation, and endothelial activation: A repeat-measures analysis in the MultiEthnic Study of Atherosclerosis (MESA). Epidemiology 26: 310-320.

Han, M.H., Yi, H.J., Ko, Y., Kim, Y.S. and Lee, Y.J. (2016). Association between hemorrhagic stroke occurrence and meteorological factors and pollutants. BMC Neurol. 16: 59.

Hassanvand, M.S., Naddafi, K., Kashani, H., Faridi, S., Kunzli, N., Nabizadeh, R., Momeniha, F., Gholampour, A., Arhami, M., Zare, A., Pourpak, Z., Hoseini, M. and Yunesian, M. (2017). Short-term effects of particle size fractions on circulating biomarkers of inflammation in a panel of elderly subjects and healthy young adults. Environ. Pollut. 223: 695-704.

Huang, F., Luo, Y., Guo, Y., Tao, L., Xu, Q., Wang, C., Wang, A., Li, X., Guo, J., Yan, A. and Guo, X. (2016). Particulate matter and hospital admissions for stroke in Beijing, China: Modification effects by ambient temperature. J. Am. Heart Assoc. 5: e003437.

Huang, K.L., Liu, S.Y., Chou, C.C., Lee, Y.H. and Cheng, T.J. (2017). The effect of size-segregated ambient particulate matter on Th1/Th2-like immune responses in mice. PLoS One 12: e0173158.

Hurst, S.M., Wilkinson, T.S., McLoughlin, R.M., Jones, S., Horiuchi, S., Yamamoto, N., Rose-John, S., Fuller, G.M., Topley, N. and Jones, S.A. (2001). IL-6 and its soluble receptor orchestrate a temporal switch in the pattern of leukocyte recruitment seen during acute inflammation. Immunity 14: 705-714.

Ilabaca, M., Olaeta, I., Campos, E., Villaire, J., TellezRojo, M.M. and Romieu, I. (1999). Association between levels of fine particulate and emergency visits for pneumonia and other respiratory illnesses among children in Santiago, Chile. J. Air Waste Manage. Assoc. 49: 154-163.

Jin, Y., Wu, W., Zhang, W., Zhao, Y., Wu, Y., Ge, G., Ba, Y., Guo, Q., Chi, X., Hao, H., Wang, J. and Feng, F. (2017). Involvement of EGF receptor signaling and NLRP12 inflammasome in fine particulate matterinduced lung inflammation in mice. Environ. Toxicol. 32: 1121-1134.

Johannesson, S., Andersson, E.M., Stockfelt, L., Barregard, L. 
and Sallsten, G. (2014). Urban air pollution and effects on biomarkers of systemic inflammation and coagulation: A panel study in healthy adults. Inhalation Toxicol. 26: 84-94.

Kang, S.H., Heo, J., Oh, I.Y., Kim, J., Lim, W.H., Cho, Y., Choi, E.K., Yi, S.M., Shin, S.D., Kim, H. and Oh, S. (2016). Ambient air pollution and out-of-hospital cardiac arrest. Int. J. Cardiol. 203: 1086-1092.

Katsouyanni, K., Touloumi, G., Samoli, E., Gryparis, A., Le Tertre, A., Monopolis, Y., Rossi, G., Zmirou, D., Ballester, F., Boumghar, A., Anderson, H.R., Wojtyniak, B., Paldy, A., Braunstein, R., Pekkanen, J., Schindler, C. and Schwartz, J. (2001). Confounding and effect modification in the short-term effects of ambient particles on total mortality: Results from 29 European cities within the APHEA2 project. Epidemiology 12: 521-531.

Kim, T.Y., Kim, H., Yi, S.M., Cheong, J.P. and Heo, J. (2018). Short-term effects of ambient $\mathrm{PM}_{2.5}$ and $\mathrm{PM}_{2.5-10}$ on mortality in major cities of Korea. Aerosol Air Qual. Res. 18: 1853-1862.

Li, W., Dorans, K.S., Wilker, E.H., Rice, M.B., Ljungman, P.L., Schwartz, J.D., Coull, B.A., Koutrakis, P., Gold, D.R., Keaney, J.F., Vasan, R.S., Benjamin, E.J. and Mittleman, M.A. (2017). Short-term exposure to ambient air pollution and biomarkers of systemic inflammation: The Framingham Heart Study. Arterioscler. Thromb. Vasc. Biol. 37: 1793-1800.

Lim, W.S., van der Eerden, M.M., Laing, R., Boersma, W.G., Karalus, N., Town, G.I., Lewis, S.A. and Macfarlane, J.T. (2003). Defining community acquired pneumonia severity on presentation to hospital: An international derivation and validation study. Thorax 58: 377-382.

Lin, M., Stieb, D.M. and Chen, Y. (2005). Coarse particulate matter and hospitalization for respiratory infections in children younger than 15 years in Toronto: a case-crossover analysis. Pediatrics 116: e235-240.

Liu, Y., Chen, X., Huang, S., Tian, L., Lu, Y., Mei, Y., Ren, M., Li, N., Liu, L. and Xiang, H. (2015). Association between air pollutants and cardiovascular disease mortality in Wuhan, China. Int. J. Environ. Res. Public Health 12: 3506-3516.

Maciejczyk, P., Jin, L., Hwang, J.S., Guo, X., Zhong, M., Thurston, G. and Chen, L.C. (2018). Association of cardiovascular responses in mice with source-apportioned $\mathrm{PM}_{2.5}$ air pollution in Beijing. Aerosol Air Qual. Res. 18: 1839-1852.

Maclure, M. (1991). A method for studying transient effects on the risk of acute events. Am. J. Epidemiol. 133: 144153.

Marshall, R.J. and Jackson, R.T. (1993). Analysis of casecrossover designs. Stat. Med. 12: 2333-2341.

Mittleman, M.A., Maclure, M. and Robins, J.M. (1995). Control sampling strategies for case-crossover studies: An assessment of relative efficiency. Am. J. Epidemiol. 142: 91-98.

Patel, M.M., Chillrud, S.N., Deepti, K.C., Ross, J.M. and Kinney, P.L. (2013). Traffic-related air pollutants and exhaled markers of airway inflammation and oxidative stress in New York City adolescents. Environ. Res. 121: 71-78.

Peng, R.D., Dominici, F., Pastor-Barriuso, R., Zeger, S.L. and Samet, J.M. (2005). Seasonal analyses of air pollution and mortality in 100 US cities. Am. J. Epidemiol. 161: 585-594.

Pope, C.A., Muhlestein, J.B., Anderson, J.L., Cannon, J.B., Hales, N.M., Meredith, K.G., Le, V. and Horne, B.D. (2015). Short-term exposure to fine particulate matter air pollution is preferentially associated with the risk of ST-segment elevation acute coronary events. J. Am. Heart Assoc. 4: e002506.

Qiu, H., Tian, L.W., Pun, V.C., Ho, K.F., Wong, T.W. and Yu, I.T. (2014). Coarse particulate matter associated with increased risk of emergency hospital admissions for pneumonia in Hong Kong. Thorax 69: 1027-1033.

Rao, K.M. (2000). Molecular mechanisms regulating iNOS expression in various cell types. J. Toxicol. Environ. Health Crit. Rev. 3: 27-58.

Ren, M., Fang, X., Li, M., Sun, S., Pei, L., Xu, Q., Ye, X. and Cao, Y. (2017). Concentration-response relationship between $\mathrm{PM}_{2.5}$ and daily respiratory deaths in China: A systematic review and metaregression analysis of timeseries studies. Biomed. Res. Int. 2017: 5806185.

Salive, M.E., Wallace, R.B., Ostfeld, A.M., Satterfield, S. and Havlik, R.J. (1993). Risk factors for septicemiaassociated mortality in older adults. Public Health Rep. 108: 447-453.

Souza, L.S. and Nascimento, L.F. (2016). Air pollutants and hospital admission due to pneumonia in children: A time series analysis. Rev. Assoc. Med. Bras. 62: 151-156.

Storms, A.D., Chen, J., Jackson, L.A., Nordin, J.D., Naleway, A.L., Glanz, J.M., Jacobsen, S.J., Weintraub, E.S., Klein, N.P., Gargiullo, P.M. and Fry, A.M. (2017). Rates and risk factors associated with hospitalization for pneumonia with ICU admission among adults. BMC Pulm. Med. 17: 208.

Tamagawa, E., Bai, N., Morimoto, K., Gray, C., Mui, T., Yatera, K., Zhang, X., Xing, L., Li, Y., Laher, I., Sin, D.D., Paul Man, S.F. and van Eeden, S.F. (2008). Particulate matter exposure induces persistent lung inflammation and endothelial dysfunction. Am. J. Physiol. Lung Cell Mol. Physiol. 295: L79-85.

Tian, L., Qiu, H., Pun, V.C., Ho, K.F., Chan, C.S. and Yu, I.T. (2015). Carbon monoxide and stroke: A time series study of ambient air pollution and emergency hospitalizations. Int. J. Cardiol. 201: 4-9.

Ueda, K., Nitta, H., Ono, M. and Takeuchi, A. (2012). Estimating mortality effects of fine particulate matter in Japan: A comparison of time-series and case-crossover analyses. J. Air Waste Manage. Assoc. 59: 1212-1218.

Ueda, K., Yamagami, M., Ikemori, F., Hisatsune, K. and Nitta, H. (2016). Associations between fine particulate matter components and daily mortality in Nagoya, Japan. J. Epidemiol. 26: 249-257.

Wang, X., Kindzierski, W. and Kaul, P. (2015). Comparison of transient associations of air pollution and AMI hospitalisation in two cities of Alberta, Canada, using a case-crossover design. BMJ Open 5: e009169. 
Weichenthal, S.A., Lavigne, E., Evans, G., Pollitt, K. and Burnett, R.T. (2016). Ambient $\mathrm{PM}_{2.5}$ and risk of emergency room visits for myocardial infarction: Impact of regional $\mathrm{PM}_{2.5}$ oxidative potential: A case-crossover study. Environ. Health 15: 46.

Xing, Y.F., Xu, Y.H., Shi, M.H. and Lian, Y.X. (2016). The impact of $\mathrm{PM}_{2.5}$ on the human respiratory system. $J$. Thorac. Dis. 8: E69-74.

Zeb, B., Alam, K., Sorooshian, A., Blaschke, T., Ahmad, I. and Shahid, I. (2018). On the morphology and composition of particulate matter in an urban environment. Aerosol Air Qual. Res. 18: 1431-1447.

Zeka, A., Zanobetti, A. and Schwartz, J. (2005). Short term effects of particulate matter on cause specific mortality:
Effects of lags and modification by city characteristics. Occup. Environ. Med. 62: 718-725.

Zosky, G.R., Iosifidis, T., Perks, K., Ditcham, W.G.F., Devadason, S.G., Siah, W.S., Devine, B., Maley, F. and Cook, A. (2014). The concentration of iron in real-world geogenic $\mathrm{PM}_{10}$ is associated with increased inflammation and deficits in lung function in mice. PLoS One 9: e90609.

Received for review, August 4, 2018

Revised, October 11, 2018

Accepted, October 13, 2018 